\title{
Crônica do Grupo Bilbao 1996-2014: uma visão desde dentro
}

\author{
A Chronicle of the Bilbao Group from Inside (1996-2014)
}

\author{
Xavier Frias Conde \\ Universidad Nacional de Educación a Distancia \\ Departamento de Filología Clásica \\ xfrias@flog.uned.es \\ [recibido 31/10/2014, aceptado 26/01/2015]
}

\section{RESUMO}

Desde 1996, a principal atividade literária de expressão galega em Madrid desenvolve-se arredor do Grupo Bilbao, um coletivo de escritores que reside na capital de Espanha e desenvolve a sua atividade literária principalmente em galego. Muitas são as questões formuladas acerca deles, questões relativas à identidade, à exotopia, ao bilinguismo, etc. Neste artigo tentamos responder a todas essas questões desde a intra-história do grupo, percorrendo a sua história ao longo destes 18 anos.

PALAVRAS CLAVE: Grupo Bilbao, literatura de expressão galega, exotopia, Madrid, identidade, O Roibén.

\section{RESUMEN}

Desde 1996, la principal actividad literaria de expresión gallega en Madrid se desarrolla alrededor del Grupo Bilbao, un colectivo de escritores que reside en la capital de España y desarrolla su actividad literaria principalmente en gallego. Muchas son las cuestiones formuladas acerca de ellos, cuestiones relativas a la identidad, la exotopía, al bilingüismo, etc. En este artículo intentamos responder a todas esas cuestiones desde la intrahistoria del grupo, recorriendo su historia a lo largo de estos 18 años.

PALABRAS CLAVE: Grupo Bilbao, literatura de expresión gallega, exotopía, Madrid, identidad, O Roibén.

\section{ABSTRACT}

Since 1996, most of the literary production in Galician was carried out by the so-called Grupo Bilbao, a group of writers living in the capital city of Spain, whose main literary language is Galician. There are dozens of questions arising around them, such as identity, exotopia, bilingualism, etc. This paper attempts to give an answer to all these questions from inside the group's intra-history by following the main hits of its history throughout the last 18 years.

KEY wORDs: Grupo Bilbao, Galician language literature, exotopia, Madrid, identity, O Roibén.

Frias Conde, X. (2015): “Crônica do Grupo Bilbao 1996-2014: uma visão desde dentro”, Madrygal (Madr), 18, Núm. Especial: $421-429$.

SUMÁRIO: 1. Introdução. 2. Tratando de definir o GB. 3. Da procedência dos seus membros. 4. Ao redor do GB: algumas falsas percepções. 5. Fases na história do GB. 6. As edições em galego(-português) desde Madrid (20112014). 7. Conclusões. 8. Referências bibliográficas. 


\section{INTRODUÇÃO}

O Grupo Bilbao (GB) nasceu em novembro de 1996 a partir de um encontro entre Vicente Araguas, Fermín Bouza e Xavier Frías Conde no café Comercial de Madrid. O terceiro deles conheceu o Araguas e o Bouza na livraria Sargadelos de Madrid em outubro de 1996, onde Vicente Araguas apresentava o seu libro $O$ gato branco. Aquele foi o embrião do Grupo Bilbao, que recebe este nome do próprio Araguas por o café Comercial estar na madrilena Glorieta de Bilbao.

Este facto tem uma importância capital, pois desde 1996 até hoje, 2014, transcorreram 18 anos em que o Grupo Bilbao tem sido o referente da literatura galega em Madrid. Evidentemente antes existiram outros grupos, o anterior ainda o Brais Pinto com a presença não muito afastada de Celso Emilio Ferreiro em Madrid, embora o GB não tivesse nunca esse componente político que sim tiveram grupos precedentes. O certo é que Madrid sempre teve presença literária galega, desde a própria Rosalía e o seu home M. Murguía, até os dias de hoje. Todavia, o GB, à diferença do Brais Pinto, é mais heterogéneo e não lhe tocou viver os tempos complicados da fim do franquismo, polo qual bem se pudo dedicar à literatura; contudo, alguns dos seus membros mais idosos, como Vicente Aráguas e Fermín Bouza, são o vínculo com os grupos anteriores.

Quando se celebraram 15 anos do nascimento do GB, em 2011, o acontecimento passou desapercebido de tudo em Galiza. Precisamente uma das questões que rodeiam o GB é o escasso eco que toda a sua atividade tem tido em Galiza ao longo da sua existência, de facto uma boa parte do aparato crítico ignora sistematicamente toda a atividade literária deste grupo.

Este texto visa recolher quais as características, os momentos e as publicações principais do GB neste período de 18 anos, contado desde dentro, por mim como um dos membros fundadores do grupo. Para isso, recupero em boa medida postagens minhas anteriores publicadas no meu blogue $O$ xapo (veja-se depois na bibliografia).

\section{TRATANDO DE DEFINIR O GB}

À hora de definir o que é o Grupo Bilbao, há que ter em conta muitos dos elementos que o caracterizam. O mais singelo é afirmar que se trata dum grupo de escritores de expressão galega que vivem em Madrid ou em derredor. Nesse sentido, tem muitos dos traços que caracteriza os grupos literários de fronteira, fenómeno também conhecido como exotopia. É uma situação que se pode refletir assim (Frias 2012: 274):

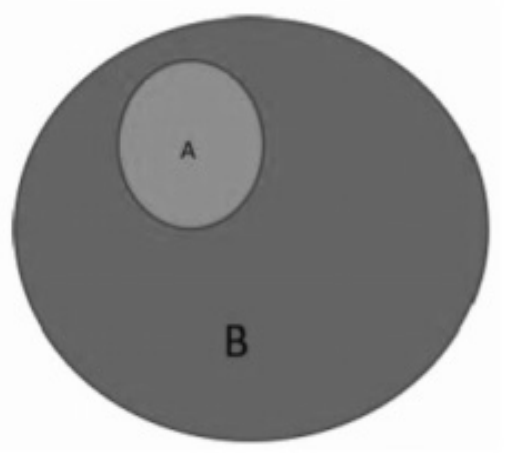

Neste gráfico representa-se uma língua $\mathrm{A}$ que é a língua literária (e em quase todos os casos a língua materna) dos escritores do GB, neste caso a língua galega. Tal língua, que eles cultivam literariamente, tem de coabitar com uma língua B (o espanhol). Este gráfico, assim visto, poderia responder à realidade dos escritores chicanos nos Estados Unidos ou dos escritores de expressão árabe em Paris na mesma, portanto é evidente que se trata de um conceito de exotopia; todavia, no caso do GB tem certas características próprias. Em primeiro lugar, não há uma mudança de país, isto é, os escritores do GB seguem a viver no mesmo Estado e a distância entre Madrid e Galiza, para os procedentes dali, é facilmente superável. Por outro lado, a distância tipológica no idioma é relativamente pequena (é uma distância GL $><$ ES, não é uma distância ES $><\mathrm{EN}$, como nos escritores chicanos, e menos ainda AR $><$ FR como é o caso dos escritores de expressão árabe em Paris). Contudo, uma questão importante é que papel tem a língua $\mathrm{B}$ nos escritores da exotopia. Não há uma resposta padrão para isto, mas no caso do $\mathrm{GB}$, em praticamente todos os casos, a língua B, o espanhol, é também língua de criação literária, pode-se 
afirmar que todos os membros do GB são escritores bilíngues, mas o que realmente consegue uma coesão maior do grupo não é a língua $\mathrm{B}$, mas a língua $\mathrm{A}$, aquilo que o singulariza no contorno em que vivem. Além disso, os escritores do GB têm uma consciência linguística muito superior à do falante comum, não existe qualquer tipo de diglossia nestes escritores.

Neste contexto, o GB converteu-se num grupo de auto-apoio para os escritores de expressão galega. Nele coincidiram várias gerações de escritores e, nalgum dos casos, até serviu de plataforma de lançamento para a carreira literária dalguns deles. O grupo é, portanto, um ponto de encontro dos escritores de expressão galega na capital da Espanha, bem como um referente literário das letras galegas em Madrid, como o foi no seu momento Buenos Aires. A Madrid continuam a chegar emigrados galegos, não se trata, em qualquer caso, de exilados; portanto, as diferenças com os movimentos de escritores da pós-guerra são notáveis. Porém, o GB, como já ficou dito, é um grupo predominantemente literário, sem pretensões políticas, como sim o foram outros grupos precedentes, ao contrário do que afirmam outros estudiosos (Acuña 2014: 287, 314).

O GB não é exclusivamente um grupo poético, é apenas um grupo literário. $\mathrm{O}$ facto de a maioria da produção dos seus membros ser poesia não exclui outros géneros, embora seja em menor medida. Não há qualquer dúvida da predominância da poesia se tomarmos em consideração o tipo de publicações dos últimos anos. Porém, até nos textos coletivos existem duas coletâneas de microficção: Madrid foi unha praia de baleas entre néboas (2011) e Hipnotopia (2012)

\section{DA PROCEDÊNCIA DOS SEUS MEM- BROS}

A primeira impressão que um tem é que todos os membros do GB são galegos emigrados a Madrid. Isto é incorreto. Muitos deles sim são galegos emigrados, mas há membros do grupo que nem são galegos. Uma das características do GB que antes não foi mencionada mas que agora sim convém citar é que na sua primeira etapa (veja-se abaixo) conseguiu atrair para si escritores sem qualquer vinculação com Galiza nem com a sua língua. Tratou-se de jovens autores que estudaram galego na UCM, principalmente da mão da leitora galega que havia naquela altura, Ana Acuña, e que se apaixonaram pela língua, até o ponto de começarem a escrever poesia em galego. Este pequeno grupo é conhecido como os escritores alógrafos do GB. Entre eles estão Luis Luna e Susana González.

Uma análise mais profunda das origens dos autores do GB permite-nos distinguir diversas procedências (Frias 2012: 275):

- Nascidos em Galiza e emigrados em Madrid: Vicente Araguas, Manuel Pereira, Fermín Bouza, Rafa Yáñez

- Filhos de galegos que viveram, ou não em Galiza: Ana Cibeira, Begoña Regueiro ou José Galán.

- Filhos de galego-falantes de fora de Galiza: Xavier Frías e Viqui Veiguela, de procedência eonaviega.

- Alógrafos: Luis Luna.

Visto o anterior, insistirei em que o elemento aglutinador não é a procedência, mas a língua. A língua galega consegue a coesão deste grupo literário. Eis a razão por que sempre me refiro ao Grupo Bilbao como um grupo de escritores de expressão galega e nunca como um grupo de escritores galegos.

Além disto, convém distinguir diversas etapas na formação do grupo a respeito do GB. Em primeiro lugar, há um núcleo fundador já mencionado acima, com os três autores que se reuniram na tertúlia para criarem o grupo: Arguas, Bouza e Frias. A eles uniram-se logo três piares do GB, considerados precisamente escritores nucleares: Manuel Pereira, Rafa Yáñez e Luis Luna. Porém, é complicado fazer uma listagem completa dos escritores que pertencem ou pertenceram ao GB, ou simplesmente que participaram em algumas das suas publicações. Citaremos a seguir algumas autoras consideradas escritoras participantes (há mulheres, e muitas) que fazem parte do grupo em ordem cronológica de chegada: Viqui Veiguela, Verónica Martínez, Begoña Regueiro 
ou Luz Pichel. Também publicaram em determinadas ocasiões poetas como Pilar Mera, Miguel Barrera, Montse Villar, Ana Cibeira ou Yolanda López que poderiam ser consideradas como escritores vinculados. Conte-se também com autores como José Galán, que continua a viver em Madrid, mas que praticamente não tem atividade literária (mas que também pode ser considerado como escritor participante).

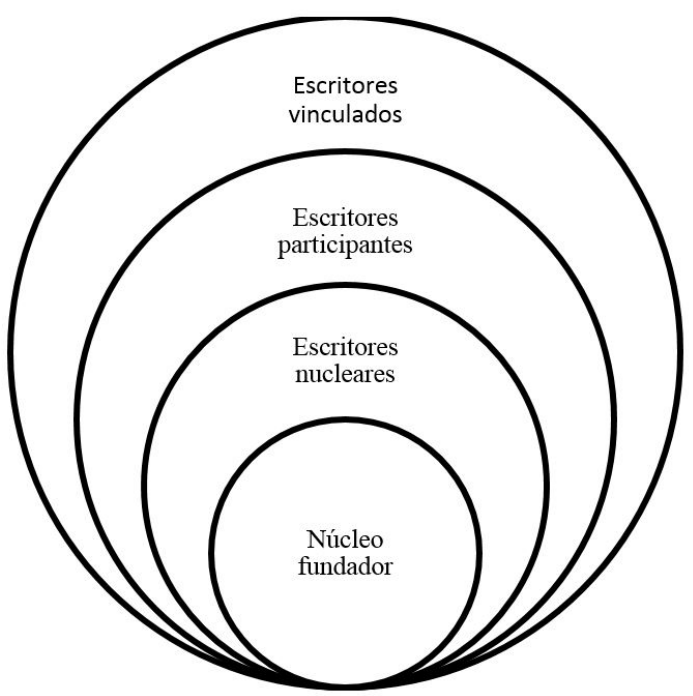

Este gráfico só responde à realidade do GB na segunda época. Não falaremos aqui em escritores cujo passo pelo grupo foi significativo na primeira época, como Cláudio Pato.

\section{AO REDOR DO GB: ALGUMAS FAL- SAS PERCEPÇÕES}

Ora bem, entorno ao GB tem-se formado uma série de maus entendidos que convém esclarecer. Se bem é certo que o GB nasceu ao redor da tertúlia do café Comercial, o grupo e a tertúlia são duas coisas diferentes de tudo. Este faladoiro iniciou-se em 1996, como já foi dito, pelos três fundadores do GB, aos quais se uniu de seguida Manuel Pereira. Desde aquela altura, a cada último sábado de cada mês, diversas pessoas combinam lá para tomar um café e falar em galego. Alguns dos que ali acodem são, com efeito, membros do GB, mas não todos. Alguns intelectuais galeguistas da pós-guerra, vínculo cos grupos anteriores, frequentaram e frequentam o café Comercial, como Alexandre Fisterra, Borobó e Sabino Torres. Nenhum deles pode ser considerado membro do GB, embora participassem eventualmente em atividades dele.

Além disso, nem todos os autores do GB frequentam as tertúlias. Portanto, identificar o GB com a tertúlia é algo absolutamente errado, embora haja uma relação inegável entre ambas as entidades. Além disso, nem todos os autores galegos que vivem em Madrid pertencem ou têm relação com o GB, como é o caso de Antonio Domínguez Rey ou Marina Mayoral. Isto pode ser representado segundo o seguinte gráfico, onde há um ponto de interseção evidente:

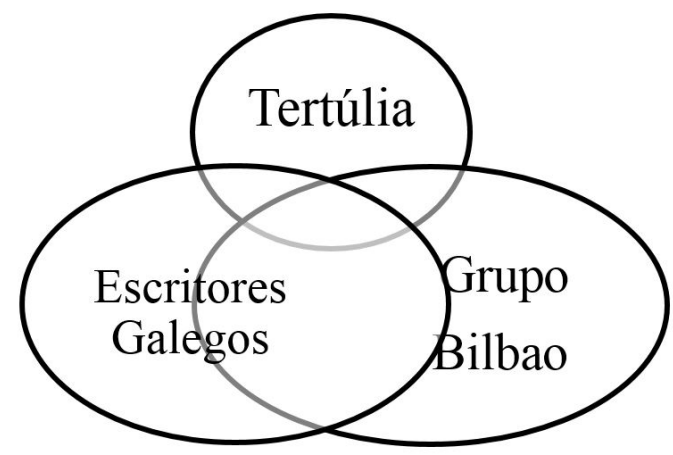

O Grupo Bilbao não é apenas um grupo poético. Parece que existe uma forte tendência a ligar o GB apenas com poesia, o qual é falso. Embora a poesia seja o género principal que eles cultivam, não é o único. Quase todos os seus membros cultivaram a narrativa e alguns dos textos coletivos da década de 2010 são, precisamente, de microficção (veja-se depois).

Como tantos outros grupos, o GB tem uma coleção de seu: $O$ Roibén, de que falaremos a seguir. Não tem nem teve uma revista própria, ainda que se fizessem muitos estudos sobre os membros do GB em Madrygal e se publicassem muitos trabalhos literários nas suas páginas de vários membros do $\mathrm{GB}$, mas tal revista, fundamental na historia do GB, não pertence ao próprio grupo, é uma revista do Seminário de Estudos Galegos da UCM. Esta revista, presente desde muito cedo nos inícios do grupo, já não é a única em que aparecem estudos sobre o grupo; também a Revista de Lengua y Literatura Catalana, Gallega y Vas$c a$ da UNED se vem ocupando do grupo desde 
2010, justo quando começa a terceira fase da história do grupo. Além disso, $O$ Roibén nunca foi uma coleção reivindicativa no sentido político, foi e é uma coleção literária que visa dar voz aos autores de expressão galega de Madrid, mas não só isso, dado que se promovem também as traduções e as edições bilíngues.

\section{FASES NA HISTÓRIA DO GB}

Outra questão importante é qual a atividade desenvolvida polo GB como grupo literário. Como já foi dito, foi e é preciso fazer promoção dos seus autores desde Madrid. Por esse motivo, o GB teve que montar as suas próprias plataformas editoriais. Neste sentido, convém distinguir três períodos na vida do grupo. O primeiro deles abrange o período de 1996-2002, de máxima atividade; o segundo período durou entre 2002-2010, em que o grupo viveu numa espécie de letargo; o terceiro é o da recuperação, e inicia-se em 2010 e continua até hoje.

O primeiro período tem duas fases. A primeira (1996-2002) é de desenvolvimento do grupo e lançamento de autores, enquanto a segunda (2002-2010) é um período de decaimento. No primeiro momento, as atividades do GB centram-se em duas questões que estão fortemente ligadas: a edição de poemários e os recitais poéticos. É assim que nasce a coleção de poesia $O$ Roibén, que alcançou 20 títulos entre 1998 e 2002, todos em formato caderno. Esta coleção representou a batizo de autores noveis e gerou uma importante atividade literária em Madrid ao redor da Galeria Sargadelos, como o importante apoio do Departamento de Filologia Românica da Universidade Complutense de Madrid, sendo o seu maior expoente Carmen Mejía Ruiz e o apoio recebido desde a revista Madrygal.

A coleção $O$ Roibén é a única coleção que está vinculada ao GB. Foi fundada em 1998 por X. Frias e R. Yáñez. Constou de vinte títulos, onde se misturaram livros coletivos com livros individuais, alguns mesmo bilíngues (asturiano-galego, romeno-galego), com presença até de geoletos galegos, como o eonaviego, que naquela altura tivo uma importante presença na coleção. Aquela primeira etapa d'O Roibén deu lugar a uma outra coleção já em formato livro, Alcálima, que deu ao prelo oito títulos, também da mão de Rafa Yáñez e Xavier Frías. Porém, seria errado considerar ambas as coleções como algo exclusivo do GB, porque nelas publicaram muitos autores, galegos e não galegos, onde houve uma tentativa de criar livros que fossem pontos de encontro entre culturas. O resultado são vinte e oito títulos poéticos com presença do galego em todos eles.

O segundo período inicia-se em 2002. A coleção $O$ Roibén decai é as atividades do grupo ficam reduzidas ao mínimo. A tertúlia do café Comercial mantém-se fielmente, mas não ajuda a impulsionar a atividade literária do Grupo. No entanto, há duas atividades que sim têm lugar durante este período. Em primeiro lugar, entre 2005 e 2009 organizaram-se desde a Casa de Galiza em Madrid as Primaveras Poéticas coordenadas pelo escritor Vicente Araguas, quem trouxe dúzias de poetas galegos para lerem as suas composições neste local. Em segundo lugar, publicou-se a coleção Alcálima (o nome foi recuperado depois para outra coleção dentro da Lastura) de poesia, em que foram publicados vários títulos. Naquela altura tentou-se continuar com o trabalho feito na etapa anterior com O Roibén, para o qual Xavier Frias e Rafa Yáñez publicaram vários títulos de autores diversos (Frias 2012: 276-279).

O terceiro período supõe o retorno do Grupo Bilbao, cuja atividade foi mínima durante oito anos (2010- ). Há um elemento novidoso: a UNED converte-se também em espaço de difusão e promoção do GB junto com a UCM. As celebrações do Dia das Letras Galegas vêm acompanhadas de livros coletivos dos autores do grupo, alternando poesia com narrativas, nomeadamente microficção. Pode-se afirmar que o retorno do grupo chega com o lançamento em 2010 do livro coletivo Marés nos pousos do café, seguido depois pelo livro de microficção Madrid foi unha praia de baleas entre néboas (2011). No ano seguinte, aparece uma primeira antologia do grupo desta segunda fase publicada pela editora madrilena Amargord. com o título de Bilbao, coordenada por X. Frias e L. Luna (2012). Depois chegou Filografias (2013), também 
como antologia coletiva, e a última por agora: Esferografias (2014). As duas últimas antologias publicadas foram editadas pela Lastura, a qual também publicou uma outra antologia, neste caso de microficção, em 2012, a já mencionada Hipnotopia, uma coleção de microstórias com uma versão em italiano.

É também nesta segunda etapa quando começam os simpósios sobre o Grupo Bilbao. O primeiro deles foi na UNED em 2012, para celebrar os quinze anos da existência do grupo, cujo eco no sistema galego passou praticamente desapercebido.

Em 2013 a recém-criada editora Lastura recupera a histórica coleção $O$ Roibén durante as Letras Galegas de 2013. Isto supõe a segunda fase na história da coleção, que amplia as suas vistas editoriais e inclui em igualdade de oportunidades o português, com duas linhas: uma monolingue (galego-português) e outra bilingue (galego-português / espanhol). Desde aquela altura foram já publicados muitos títulos, abrindo-se duas linhas, uma delas de textos monolíngues em galego-português e outra de textos bilíngues em galego-português com outras línguas, a maioria das vezes o espanhol; são conhecidas como série vertical e série horizontal respetivamente. Trataremos disso a seguir.

\section{AS EDIÇÕES FEITAS EM GALEGO (-PORTUGUÊS) DESDE MADRID (2011- 2014)}

Já ficou dito que a Lastura assumiu como uma parte importante da sua filosofia editorial a publicação dos textos galego-portugueses do Grupo Bilbao. Porém, não é a única editora que publicou textos de membros do GB. Já foi mencionada a antologia Bilbao (2011) publicada pela editora Amargord de Madrid. A este livro somaram-se posteriormente outros dois mais também de dois autores do Grupo Bilbao em formato bilingue. O primeiro é Obra reunida 1994-2008 (2012) de Verónica Martínez Delgado e o segundo é Tatuaxes / Tatuajes de (2013) Manuel Pereira Valcárcel.

Junto com a Amargord, é a Lastura que publica a maioria dos textos dos escritores galegos. Já foi mencionada a coleção $O$ Roibén, cuja primeira fase existiu entre 1998-2002, mas que ressuscitou em 2012. Em 2013, a coleção diversifica-se e dá lugar a duas séries, tal como já foi também mencionado. Os primeiros textos d'O Roibén da segunda época são também em formato caderno, mantendo a essência do que foi a coleção na sua primeira época, mas aos poucos vai alcançando certa sofisticação e bem logo dá o salto para o formato de livro.

Em maio de 2013, coincidindo é lançada toda uma série de cadernos poéticos, de autores como Viqui Veiguela, Beatriz Hernanz, Rafa Yáñez, etc. (a lista completa ver-se-á na bibliografia final). Alguns daqueles cadernos iniciais foram depois reeditados como livros.

Nesse mesmo ano, a diversificação da coleção $O$ Roibén permite que, junto com a edição de textos em galego-português, apareçam textos bilíngues. A estreia desta nova série será na Expoesia de Sória em julho de 2013.

\section{CONCLUSÕES}

Ignorar a existência do Grupo Bilbao na história das Letras Galegas não é nem só injusto, mas também um erro que não faz mais do que empobrecer o panorama literário em galego. Muito pouco espaço foi dedicado à existência deste grupo nos círculos acadêmicos galegos por razões que não ficam muito claras. Quem escrever a história da literatura em língua galega no futuro terá que olhar também para Madrid e atender para este coletivo de escritores que nos últimos anos do século XX e nos primeiros do XXI fizeram literatura em galego em Madrid, mas nem só isso, também serviram e servem de ponte entre culturas, sempre desde uma posição de grupo literário, sem pretensões políticas de qualquer género.

Ficam ainda muitas coisas para dizer acerca do Grupo Bilbao. Ainda há muito a investigar, é claro, mas também é verdade que o GB não é uma história fechada, porque, embora tenha tido momentos de declínio, é inegável que está muito vivo. Desde 2010 parece estar a viver um segundo momento doce, embora não tão espetacular como nos anos da mudança do século. Como um grupo dinâmico que é, por ele passam autores que deixam a sua pegada. 
Já ficou dito que o Grupo Bilbao é uma fronteira literária, um grupo de exotopia, com as suas peculiaridades por estar composto de escritores de expressão galega em Madrid, tornando-o substancialmente diferente dos grupos de escritores de expressão espanhola nos Estados Unidos. Não se pode esquecer que nem todos os escritores de expressão galega que vivem em Madrid estão ligadas ao Grupo Bilbao, porque, na verdade, não há critérios estabelecidos ou padrões que os escritores pertencem ou não ao grupo Bilbao, porque não é algo institucionalizado.

Além disso, não podar negar a estreita relação entre a tertúlia mensal no café Comercial que deu origem ao grupo e do próprio grupo, mas a verdade é que, apesar de ser dois elementos ligados são duas realidades separáveis, desmontáveis.

\section{REFERÊNCIAS BIBLIOGRÁFICAS}

\section{BIBLIOGRAFIA GERAL}

ACUÑA, Ana (2012): “Os primeiros anos do Grupo Bilbao (1996-2001)", Revista de lenguas y literaturas catalana, gallega y vasca 17, pp. 261-272.

(2014): Conciencia política e literatura galega en Madrid (1950-2000). Vigo: Xerais.

Arias Chachero, Patricia (2013): "Lastura e O Roibén: unha editorial idealista para unha colección de libros de calidade", em Grial. Revista galega de cultura 201, pp. 91-94.

BAtlló, José (1980): “Literatura y periferia”, Camp de l'arpa. Revista de Literatura 75, p. 5.

CABo, Manuel (2011): "Exotopía y emergencia: La hija del mar de Rosalía de Castro", en Literatura, Espaço, Cartografias. Portugal: Centro de Literatura Portuguesa.

Frías Conde, Xavier (2007): "Poesía gallega contemporánea en Madrid: el grupo Bilbao", Cuadernos del Ateneo 24, pp. 71-110.

- (2012). “Os 15 anos do Grupo Bilbao: algunhas reflexións", Revista de lenguas y literaturas catalana, gallega y vasca 17, 273-282.

Frías Conde, Xavier e Luis Luna (2014): "Exotopía e literatura de fronteira galegas: O caso do Grupo Bilbao", Revista de lenguas y literaturas catalana, gallega y vasca 19, pp. 201-211.

García, Xosé Lois (1984): Escolma da poesía galega 1976-1984. Barcelona: Sotelo Blanco Edicións.

(1999): Alén do azul (Unha ducia de poetas galegos en Catalunya). A Coruña: Ediciós do Castro.

Louzao Outeiro, Miguel (2006): Letras de Cal na produción poética galega dos 90. A Coruña: Laiovento.

LunA, Luis (2010): “A colección O Roibén, vieiro de expresión poética do Grupo Bilbao”, Revista de lenguas y literaturas catalana, gallega y vasca 15, pp. 89-101.

(2012): “A colección «O Roibén», vieiro de expresión poética do Grupo Bilbao”, Revista de lenguas y literaturas catalana, gallega y vasca 17, pp. 283-296.

(2012): "Xavier Frías Conde en la colección "O Roibén”. La relevante contribución poética de uno de los fundadores del Grupo Bilbao", Madrygal. Revista de estudios gallegos 15 , pp. 77-85.

MeJíA, Carmen (2012): “As poéticas do Grupo Bilbao: espazos e cidades”, Revista de lenguas y literaturas catalana, gallega y vasca 17, pp. 297-304. 
Palomares, Verónica (2012): "Los paisajes perdidos de Vicente Araguas", Revista de lenguas y literaturas catalana, gallega y vasca 17, pp. 305-312.

PociÑA, Andrés José (2012): “A poesía de Xavier Frías Conde”, Revista de Lenguas y literaturas catalana, gallega y vasca 17, pp. 313-318.

Regueiro SAlgado, Begoña (2006): "Manuel Pereira Valcárcel: poesía da Experiencia na Galicia actual", Madrygal. Revista de estudios gallegos 9, pp. 103-113.

- (2012): "Manuel Pereira ou a poética da precisión”, Revista de lenguas y literaturas catalana, gallega y vasca 17, pp. 319-338.

RegueIro, Natalia (2001): "A transversal ponte intercultural do Grupo Bilbao", O Espello. Suplemento literario de A Freita 8, pp. 26-29.

SEARA, Teresa (2001): “«O Roibén»: Literatura galega en Madrid”, Dorna. Expresión poética 27, pp. 163-167.

TARrío Varela, Anxo (1994): Literatura Galega: Aportacións a unha historia crítica. Vigo: Xerais.

VAlCÁrcel, Xulio (1999): “Poetas galegos en Madrid”, El Ideal Gallego 07/03/1999, p. 21.

\section{BIBLIOGRAFIA LITERÁRIA}

O Roibén na primeira etapa

Conde, Adela, Crisanto Veiguela e Xavier Frias (1998): Carreiros. Madrid: O Roibén.

CuRIESES, Óscar e Luis LunA (2000): Hidroemas. Madrid: O Roibén.

(2002): Ignicións. Madrid: O Roibén.

D‘LOM, Covadonga (2001): A soidade dos números primos. Madrid: O Roibén.

Eminescu, Mihai (2002): Poeme postume/Poemas póstumos. Madrid: O Roibén.

Frias Conde, Xavier (2000): Azul e terra. Poesía eonaviega 1997-1999. Madrid: O Roibén. (2001): Lar de lúa. Madrid: O Roibén.

(2001): Canto de Nedara. Madrid: O Roibén. (2002): Axarquia. Madrid: O Roibén.

Galán, José (2001): Alquimia soñada. Madrid: O Roibén.

GonzÁlez, Susana e Victoria Veiguela (2001): Simbiose. Madrid: O Roibén.

Martínez Delgado, Verónica (2002): Deshabitada e sen verdugo. Madrid: O Roibén.

Pereira, Manuel (1998): Todo morte. Madrid: O Roibén (reed. 2006, Ediciós do Castro).

Piñán, Berta, Humberto González e Alfonso Velázquez (1999): Xeitos de falar. Madrid: O Roibén.

Solla, Carlos (1999): Xábregho. Madrid: O Roibén.

(2001): Terras raras. Madrid: O Roibén.

Veiguela, Crisanto (2001): A vida sempre e sobretodo. Madrid: O Roibén.

Veiguela,Victoria (2002): O ouvido e o calado. Madrid: O Roibén.

VV.AA. (1998): Comercial. Madrid: O Roibén. 
YÁÑEz, Rafael (2000): Onte chovía. Madrid: O Roibén.

(2001): Lembranzas e olvidos dun estraño. Madrid: O Roibén.

O Roibén na segunda etapa (série vertical)

Abajo, Lourdes de (2013): Aniquilación miña. Ocaña: Lastura.

Frias Conde, Xavier (2013): Azul memória. Ocaña: Lastura.

- (2014): Manual de saudades. Ocaña: Lastura.

Hernanz, Beatriz (2013): A peregrina do vento. Ocaña: Lastura.

Martínez, Verónica (2013): Cartapedra. Ocaña: Lastura.

Veiguela, Victoria (2013): Vendo pasar o mundo. Ocaña: Lastura.

Villanueva, Milagros (2013): A la lluna de València / A la luna de Valencia / À lua de Valencia. Ocaña: Lastura.

YÁÑEZ, Rafael (2013): Axóuxeres da melancolía. Ocaña: Lastura.

Outras publicações

Araguas, Vicente e Manuel Pereira (coord.) (2001): En tránsito. Poesía galega en Madrid. Sada: Ediciós do Castro.

Frias Conde, Xavier e Luis Luna (eds.) (2012): Bilbao, antoloxía de poesía galega en Madrid. Madrid: Amargord.

FRIAS CONDE, Xavier (coord.) (2014): Esferografias. Ocaña: Lastura.

Martínez Delgado, Verónica (2012): Obra reunida 1994-2008. Madrid: Amargord.

Pereira, Manuel (2012): Tatuaxes / Tatuajes. Madrid: Amargord.

VV.AA. (2001): Muller de doce sal. Homenaxe a Inés Canosa. Gijón: VTP.

VV.AA. (2010): Marés nos pousos de café. Mostra de poetas de expresión galega en Madrid. Pontevedra: El Taller del Poeta.

VV.AA. (2011): Madrid foi unha praia de baleas na néboa. Gijón: AEN.

VV.AA. (2012): Hipnotopía en doses pequenas. Ocaña: Lastura.

VV.AA. (2013): Filografias. Ocaña: Lastura.

\section{BIBLIOGRAFIA VIRTUAL}

Blogue O xapo: http://frantzferentz.blogspot.com [consulta 10/2014]. 